\title{
ANREL
}

\section{Climate-Water Impacts on Interconnection-Scale Electricity System Planning}

Stuart M. Cohen ${ }^{1}$, Ana Dyreson ${ }^{1}$, Jordan Macknick ${ }^{1}$, Ariel Miara ${ }^{1,2}$, Vincent C. Tidwell ${ }^{3}$, Nathalie Voisin ${ }^{4}$, Sean W.D. Turner ${ }^{4}$, and Michael Bailey ${ }^{5}$

${ }^{1}$ National Renewable Energy Laboratory; ${ }^{2}$ City University of New York; ${ }^{3}$ Sandia National Laboratories; ${ }^{4}$ Pacific Northwest National Laboratory; ${ }^{5}$ Western Electricity Coordinating Council

\section{Background \& Motivation}

\section{Stakeholder-Driven Modeling and Collaboration}

- U.S. Department of Energy National Laboratories have cutting-edge capabilities for studying climate-water-electricity interactions that can assist in answering questions that cannot be addressed with typical industry tools

- The Western Electricity Coordinating Council provides a practical perspective for power system decision-making and what is important to industry

$$
\text { stakeholders }
$$

\section{Research and Analysis Questions}

1. How could future climate and water availability affect WECC investment decisions, dispatch decisions, and grid reliability?

2. How do climate and water impacts change under varying climate projections and electric system drivers?

3. How could the role of hydropower in the electricity system change under future climate and water conditions?

\section{Methods}

The Regional Energy Deployment System (ReEDS) with Climate-Water Impacts

- NREL's flagship model for simulating U.S. electricity generation and transmission investment and operation through 2050

- 134 regions for demand, water, $\mathrm{PV}$;

356 regions for wind, CSP

- 17 intra-annual time-slices for seasonal and diurnal dispatch

- Temperature impacts on load, generator performance, and transmission capacity

- CUNY Water Balance Model converts precipitation projections to thermal cooling water and hydropower availability

\section{Four Infrastructure Expansion Scenarios}

1. REF: default ReEDS v2018 assumptions

2. LOW.VG.COST: NREL ATB 2018 Low Cost case for wind and solar

3. HIGH.VG.COST: NREL ATB 2018 High Cost case for wind and solar

4. ELEC: Transportation and building electrification increases electricity

demand and adds demand flexibility

ATB: NREL Annual Technology Baseline

\section{Five Future Climate Conditions}

1. NOCLIM: Static climate conditions

+ Four temperature/precipitation alternatives from climate model simulations

2. HOTDRY: IPSL-CM5A-LR RCP 8.5

3. HOTWET: MIROC-ESM-CHEM RCP 8.5

4. COOLDRY: IPSL-CM5A-LR RCP 4.5

5. COOLWET: GFDL-ESM2M RCP 4.5

\section{Results}

\section{WECC Power Capacitv Investments}

REF.NOCLIM L.VG.COST.NOCLIM HIGH.VG.COST.NOCLIM ELEC.NOCLIM

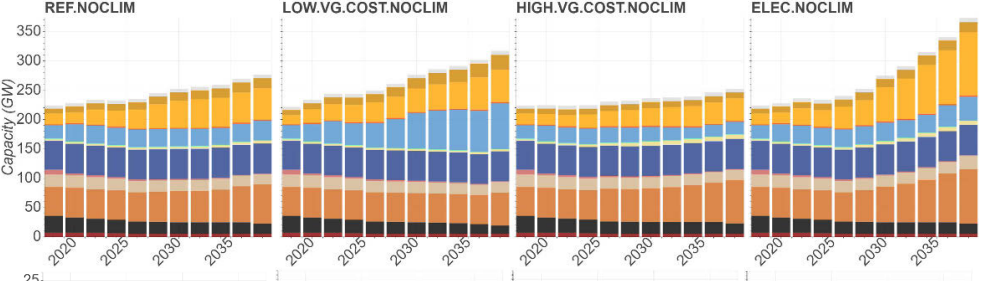

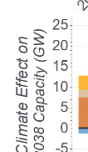

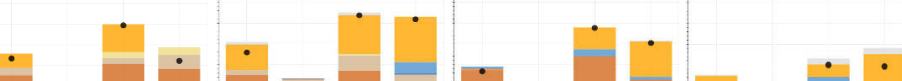

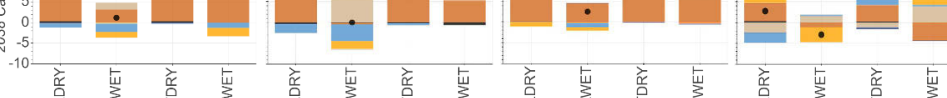

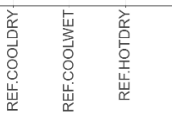
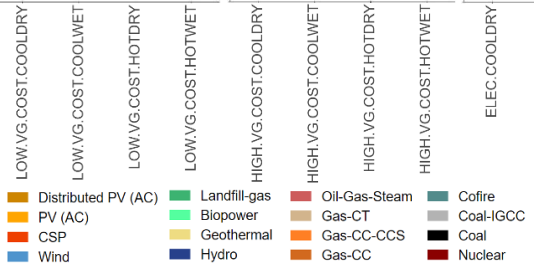

System Costs and Electricity Prices
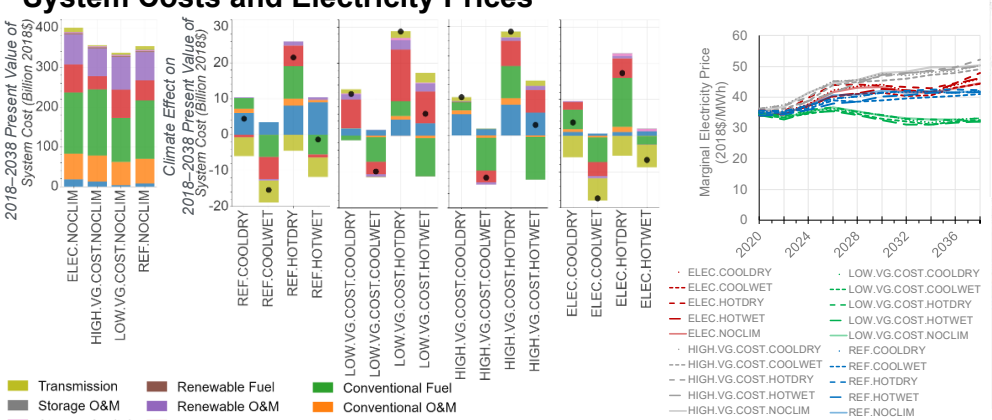

Regional Impacts on Power Capacity
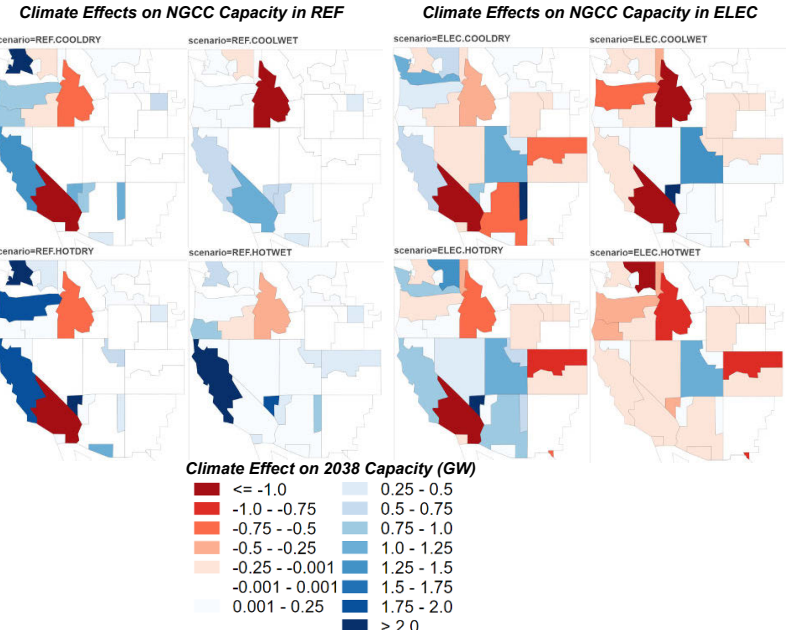

Climate Effects on PV Capacity in REF

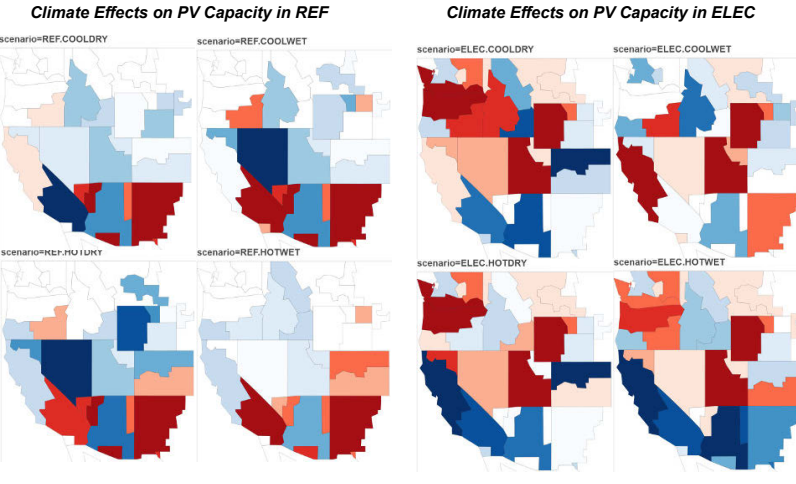

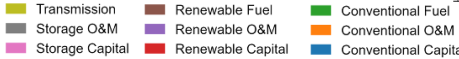

\section{Key Takeaways}

Regional and State-Level Capacity Expansion

1. Climate impacts on hydropower generation could affect future WECC capacity planning

2. Flexible and peaking capacity or flexible demand can help respond to temperature-induced load growth

3. State and sub-state impacts could depend on local resources and system configuration

\section{System Economics}

1. Heat-driven demand increases can lead to higher system costs, while increased hydropower generation can reduce system costs

2. Underlying technology costs and demand projections can influence total system costs as much as future climate conditions

3. Climate impacts on electricity prices appear small compared to the influence of technology assumptions 